\title{
Optimisation of traction and fixing systems in suspended monorails
}

\author{
J. Yunta, D. Fernandez, D. Garcia-Pozuelo, V. Diaz, B. L. Boada \\ \& M. B. Ramírez \\ Departamento de Ingeniería Mecánica, \\ Instituto para la Seguridad de los Vehículos Automóviles (ISVA), \\ Universidad Carlos III de Madrid, Spain
}

\begin{abstract}
Means of transport are a key point in the development of countries and the population interconnection, so the continuous improvement of them is an obligation and a challenge as well. The mean of transport selected for improvement is the monorail, which serves as a single rail track to transport cargo or passengers. In most cases, the monorail drives around suspension, but can also drive at ground level or tunnels. The aim of this work is the analysis of the optimisation design and technical feasibility of the traction and fixing systems of the monorail. A comparative technical analysis of these systems has been carried out to quantify them, assessing the strengths and weaknesses. Once the system idea to develop and optimise is defined, basic parameters and characteristics of the system are detailed, commercial elements are selected and a traction-fixing system model is modelled. The traction-fixing system has also been optimised with various loading limited conditions like static, modal and thermal analysis. FEM with Abaqus/CAE and CAD-CAM modelling with AutoCAD have been used in this work.

Keywords: suspended monorail, optimisation, comparative technical analysis, design alternative, FEM, computer simulations, 3D modelling.
\end{abstract}

\section{Introduction}

The monorail is a mean of transport in which carriages are moved in suspension or on a single rail structure and they are used for carrying passengers or cargo [1]. Throughout history [2], monorail systems introduced several enhancements until 
the 1970s. This decade is considered to be the beginning of modern times of the monorail. Monorail operating systems, excluding magnetic monorails, can be divided into three groups: straddle-type, double-flanged steel wheels, and SAFEGE monorails. The most widely used is the straddle-type, in which carriages straddle a beam, like the Chongqing monorail system that is shown in fig. 1 .

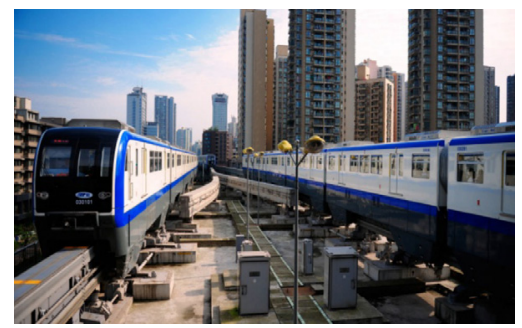

Figure 1: $\quad$ Straddle-type [3].

SAFEGE and double-flanged monorails are suspended. In case of Wuppertal Schwebebahn (WS), it has steel wheels and the track is a single rail (fig 2). In contrast to SAFEGE monorail, which uses rubber-tyres and the track is a hollow box (fig. 3).

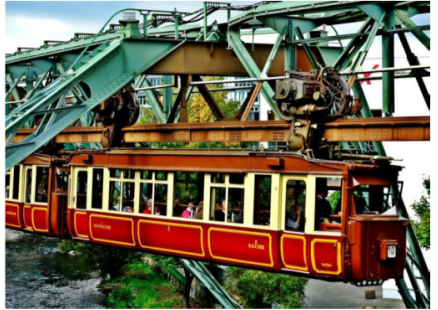

Figure 2: $\quad$ Double-flanged [4].

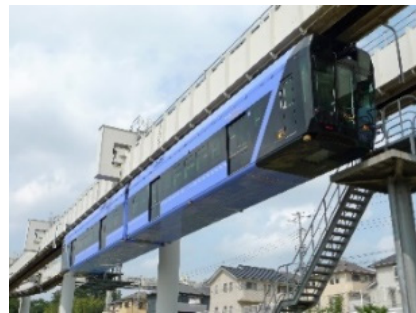

Figure 3: SAFEGE [5].

Technology available in these monorails dates from the 50s. Due to the stagnation of monorail technology, many companies have implemented projects to develop a competitive transport following the concept of monorail, in order to find a solution to the current transportation challenges. Companies such as SkyTrain Corporation (STC) [6] and Personal Rapid Transit (PRT) [7] are launching new projects.

In this paper, a study of the main analysis of the different technologies of monorails has been carried out [8-10]. By means of analysing the weaknesses of existing systems and observing where there is not currently any monorail system which predominates over the rest, it is possible to question the technology with which monorails have been equipped during the last 40 years. 


\section{Methodology}

Analytical calculations have been performed in this to select the components and determine the specifications of the developed system. The design optimisation process has been carried out using CAD (Computer Aided Design) and FEM (Finite Element Method). To summarize, the process followed throughout the work is shown in fig. 4.

\begin{tabular}{|c|c|c|c|c|c|}
\hline $\begin{array}{l}\text { State of } \\
\text { art }\end{array}$ & & $\begin{array}{c}\text { Detailed } \\
\text { engineering }\end{array}$ & & $\begin{array}{c}\text { System } \\
\text { modelling }\end{array}$ & \\
\hline$\bullet$ & $\bullet$ & $\bullet$ & $\bullet$ & - & $\bullet$ \\
\hline & $\begin{array}{l}\text { nceptual } \\
\text { lesign }\end{array}$ & & $\begin{array}{c}\text { Optimisation } \\
\text { design }\end{array}$ & & $\begin{array}{c}\text { Design } \\
\text { alternative }\end{array}$ \\
\hline
\end{tabular}

Figure 4: Work steps.

\subsection{Conceptual design}

In this step, a comparative analysis (qualitative and quantitative) has been developed in order to determine the strengths and weaknesses of each system and to compile the largest possible number of strong points in the final design alternative. The analysis was carried out taking as reference straddle-type (Seattle, Hitachi and Scomi) and suspended monorails, in particular SAFEGE monorails (Mitsubishi and Siemens H-Bahn) and double-flanged steel wheels monorails (WS).

In order to compare systems they must all be in the same reference system. In this study the features were referenced with respect to a single carriage, regarding the total number of carriages that each monorail has in a regular operation. When there was no tractor engine in the carriages, tractor carriages were used for comparative analysis.

First of all, a qualitative analysis was done, which was necessary to assess systems because not all the technical characteristics are expressed numerically, e.g. infrastructure or safety. For others, however, it was enough to order them from high to low to know which one is better, e.g. maximum speed. These features were: speed, consumption, capacity, maintenance, safety, number of drive and guide wheels, infrastructure, mass and number of engines.

The quantitative analysis that was carried out consisted in the numerical valuation of the characteristics previously cited. The aim was to quantify the strengths of each system, which can be done by scoring each system with a percentage. In this way, it is possible to know which one is better. Each characteristic had a percentage value that reflected its importance in the set. The percentages assigned to each characteristic were as follows:

- 15\%: speed, capacity and infrastructure.

- 10\%: maintenance, consumption and number of drive and guide wheels.

- 5\%: safety, number of engines and mass.

Because some features were directly connected, as in the case of consumption and number of engines, all systems have strengths and weaknesses. For this 
reason, it was necessary to assess which feature were most influential in order to consider a system better than another.

The analysis showed that the WS monorail was the most distinguished, with a rating of $74.7 \%$, followed by the Alweg systems, in particular the Seattle monorail with a rating of $56.3 \%$. The results of the analysis showed also that overall WS had more advantages than the others in number of engines, consumption, number of wheels and maintenance. It corresponds to the fact that WS is the only one with steel wheels (as shown in fig. 5). In terms of infrastructure and safety, SAFEGE monorails obtained the highest marks. It corresponds to the fact that the track in a steel box shape is advantageous (fig. 6). This kind of infrastructure facilitates the operation in adverse weather conditions.

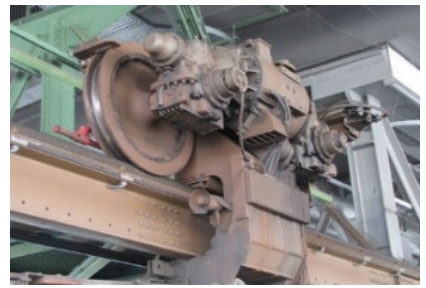

Figure 5: WS traction system [11].

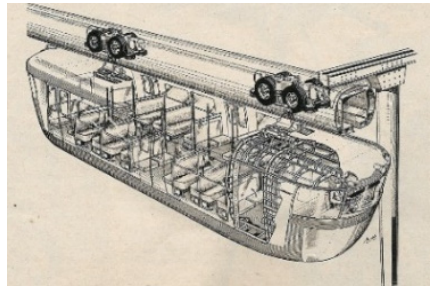

Figure 6: SAFEGE infrastructure [12].

Once the strengths and weaknesses of each system were known, and which one is better overall, a new design is considered taking into account the strengths of the previous studied design and its technical feasibility. The mark of the mixed system is shown in Table 1.

Table 1: Comparative analysis of the system to be developed.

\begin{tabular}{|c|c|c|c|c|c|}
\hline \multicolumn{2}{|c|}{ Feature } & System & Percentage & Value & Mark (\%) \\
\hline \multicolumn{2}{|l|}{ Speed } & WS & $15 \%$ & 4 & 7.50 \\
\hline \multicolumn{2}{|c|}{ Capacity } & Hitachi & $15 \%$ & 8 & 15.00 \\
\hline \multicolumn{2}{|c|}{ Infrastructure } & Mitsubishi & $15 \%$ & 7.5 & 14.06 \\
\hline \multicolumn{2}{|c|}{ Maintenance } & WS & $10 \%$ & 8 & 10.00 \\
\hline \multicolumn{2}{|c|}{ Number of drive wheels } & WS & $10 \%$ & 8 & 10.00 \\
\hline \multicolumn{2}{|c|}{ Number of guide wheels } & WS & $10 \%$ & 8 & 10.00 \\
\hline \multicolumn{2}{|c|}{ Consumption } & WS & $10 \%$ & 7 & 8.75 \\
\hline \multirow{2}{*}{ Safety } & $\mathrm{A}$ & Mitsubishi & $2.50 \%$ & 5 & 1.56 \\
\hline & $\mathrm{B}$ & Mitsubishi & $2.50 \%$ & 7 & 2.19 \\
\hline \multicolumn{2}{|c|}{ Number of engines } & WS & $5 \%$ & 6 & 3.75 \\
\hline \multicolumn{2}{|l|}{ Mass } & Hitachi & $5 \%$ & 4 & 2.50 \\
\hline & & & & & $\begin{array}{l}\text { TOTAL: } \\
85.31 \%\end{array}$ \\
\hline
\end{tabular}

Table 1 shows that a new system would improve the features discussed in the previous comparison, in which the maximum mark corresponded to the WS monorail (74.7\%). With the exceptions of mass and capacity, WS and SAFEGE monorails dominate the alternative design. 
This fact suggests that the best way to improve existing systems should be based on a mixture of SAFEGE and double-flanged type systems to obtain a traction-fixing system with electric propulsion.

Taking these monorails as a reference, an alternative design was proposed with eight steel wheels and four shafts, each one with an electric motor, as it is shown schematically in fig. 7. Steel wheels, as opposed to tyres, allow the system to be guided along the track, allowing for a reduction in the number of wheels and the risk of puncture thereof [13].

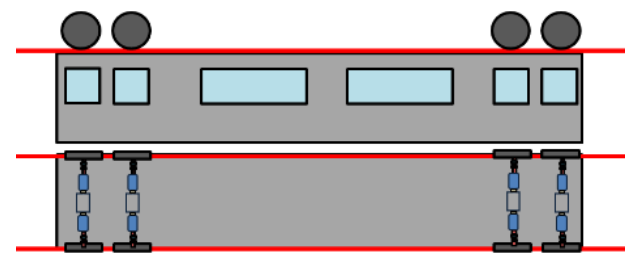

Figure 7: Scheme of the design alternative.

\subsection{Detailed engineering}

Fig. 8 shows the method that has been carried out in this step, which has as its aim the selection of components. The next sections describe the four phases in which this step was divided.

\begin{tabular}{|c|c|}
\hline \multirow{3}{*}{ Phase 1} & System capacity \\
\hline & Total mass of the system \\
\hline & Traction effort required. Performance calculating \\
\hline \multirow{3}{*}{ Phase 2} & Traction system configuration \\
\hline & Engine selection \\
\hline & Reduction gears selection \\
\hline \multirow{3}{*}{ Phase 3} & Estimating loads \\
\hline & Calculation of shaft diameter \\
\hline & Fatigue study \\
\hline \multirow{3}{*}{ Phase 4} & Bearings selection \\
\hline & Estimation of the maximum shaft deflection \\
\hline & Couplings selection \\
\hline
\end{tabular}

Figure 8: Detailed engineering phases.

\subsubsection{Phase 1}

Once the concept of traction-fixing system was established, the capacity of the system was determined taking into account the percentage of seats and the carriages dimensions that WS and Siemens H-Bahn had. Based on these assumptions, the capacity comes to 106 passengers, $30 \%$ of them seated. 
Finally, the total mass of the system comes to $19,786 \mathrm{~kg}$, taking into account that the mass of passengers corresponds to $45 \%$ of the total mass. This percentage is similar to the carriages which were taken as reference. $20 \%$ extra mass for possible overcrowding situations was included.

\subsubsection{Phase 2}

In order to select the engines, which propel the system, it was firstly necessary to calculate the tractor effort required on the drive wheels to overcome the drag force. The resulting tractive effort $440 \mathrm{~kW}$, considering a critical speed of $5 \mathrm{~km} / \mathrm{h}$ and $20 \%$ mechanical losses. A system with four $110 \mathrm{~kW}$ electric engines was selected. The selected engine that met with that requirement was the Siemens 1LG4.

Regarding the selection of reduction gears, the decisive factor was the reduction ratio between the engine and wheels. It was necessary to determine the wheel speed, prefixing the diameter thereof. Finally, the Siemens Flender Sip reduction gear was selected, eight in total, one for each wheel.

\subsubsection{Phase 3}

The third phase of detailed engineering is focused on the calculation of the shaft diameter which carries the torque from the reduction gear. The diameter was analytically determined by means of the estimation of the loads it was subjected to. The elements taken into account for the calculation were carriage, engine and reduction gear, which were selected previously.

The procedure used for shaft diameter calculation was proposed by the ASME Code [14], which purposes the eqn (1) to calculate the shaft diameter:

$$
d^{3}=\frac{16}{\pi \cdot \sigma_{P}} \cdot\left(\left(C_{f} \cdot M\right)^{2}+\left(C_{t} \cdot T\right)^{2}\right)^{\frac{1}{2}}
$$

This equation considers the combination of torsion (T) and flexion (M) maximum efforts. It also includes the maximum permissible stress $\left(\sigma_{P}\right)$, and the coefficients $C_{f}$ and $C_{t}$ which are related to flexion and torsion moments, respectively.

Taking into account that the material used for the shaft construction was the AISI 1050 cold laminated steel [15], the eqn (1) had a result of $120 \mathrm{~mm}$. In order to check the numerical calculation a fatigue study using the Goodman Criteria [16, 17] was carried out. It showed, as its most significant result, that the shaft life was infinite.

\subsubsection{Phase 4}

The selection of bearings and couplings was made taking into account the shaft diameter that was calculated previously, as well as, the output and the input diameter of engines and reduction gears selected.

To put the bearings and couplings in the correct place, it was essential to analyse the maximum shaft deflection, which depended on the distance between them. Admissible values for the loading conditions applied were obtained. Fig. 9 shows the elements that are part of the traction system for a single pair of wheels.

Table 2 lists the mechanical components selected and the main characteristics of the system developed in this paper. 


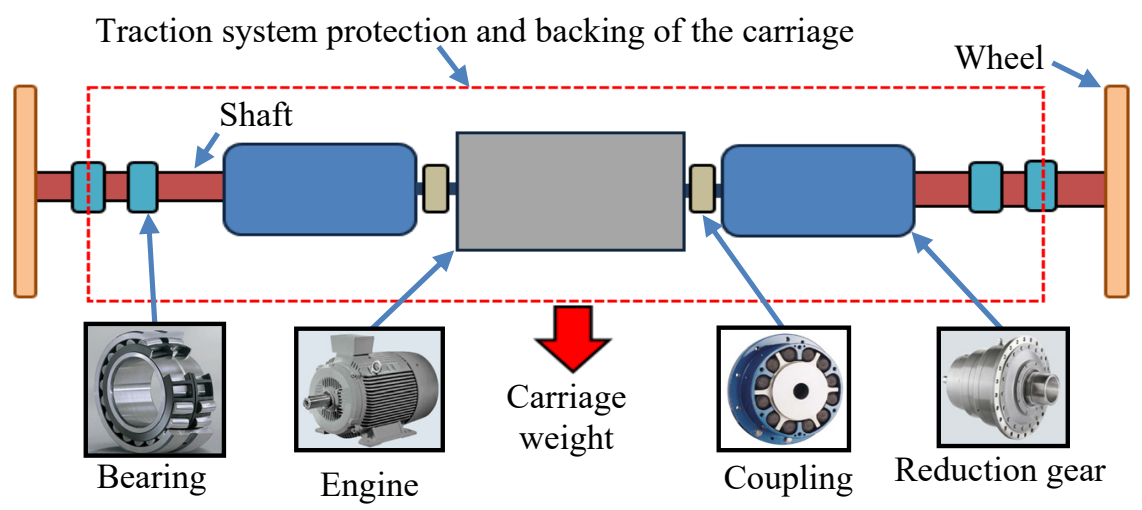

Figure 9: Scheme of the design alternative traction system.

Table 2: $\quad$ Features of the system developed.

\begin{tabular}{|l|l|}
\hline Number of carriages & 1 \\
\hline Capacity & 106 passengers \\
\hline Engines & 4 Siemens 1LG4 110kW engines \\
\hline Reduction gears & 8 Siemens Flender Sip reduction gears \\
\hline Couplings & 8 Renold Hi-Tec couplings RB \\
\hline Bearings & 16 SKF bearings \\
\hline Maximum speed & $110 \mathrm{~km} / \mathrm{h}$ \\
\hline Wheels & 8 steel wheels \\
\hline
\end{tabular}

Once the kinematic chain was developed, the next step was the optimisation of the fixing system that joins the traction system with the carriage. The main idea behind the optimisation process, that is described in the next section, was to design and optimise the fixing system (the traction system protection and backing of the carriage (as is shown in fig. 9)) allowing the contact between the track and the monorail, as well as, the supporting the weight of the carriage.

\subsection{Design optimisation}

Design optimisation consisted of an iterative process, taking into account a factor of safety of 1.5. The process started with initial model analysis, considering the worst load condition. Successive modifications to achieve the final optimised model. The final model was analysed under different load conditions, among which were: all passengers on one side of the carriage (considered the worst load condition), passengers evenly distributed, lateral wind load, thermal analysis and modal analysis. In the thermal analysis were applied the same loads that were applied in case of passengers evenly distributed, adding temperature conditions.

As the fixing-traction system and the carriage are joined by bolts, the loads were applied directly in the holes in which they would be located. Table 3 sums 
up the loads applied per bolt in each case, taking into account that the total number of bolts were 128. Note that in case of all passengers on one side of the carriage, the bolts of the other side (type 2) only support the weight of the structure.

Table 3: $\quad$ Loads applied (in Newtons).

\begin{tabular}{|c|c|c|c|}
\hline Load conditions & Bolt type & Vertical load & Lateral load \\
\hline \multirow{2}{*}{ All passengers on one side } & 1 & 1640 & 0 \\
\cline { 2 - 4 } & 2 & 503.8 & 0 \\
\hline \multirow{2}{*}{ Passengers evenly distributed } & 1 & 1072 & 0 \\
\cline { 2 - 4 } & 2 & 1072 & 0 \\
\hline \multirow{2}{*}{ Lateral wind load } & 1 & 1072 & 56 \\
\cline { 2 - 4 } & 2 & 1072 & 56 \\
\hline
\end{tabular}

Different types of steel have been selected, mainly AISI 1050 for the shaft and A36 for the optimised structure. Although there are elements of the same material, the thickness thereof may be different, so it was taken into account as a design variable. The selection of materials was carried out keeping in mind properties and market price as well.

One of the main purpose of the optimisation process was to make the structure lighter (e.g. the roof) without jeopardising the resistance of the structure. Some of the intermediate steps of the optimisation process are shown in fig. 10.

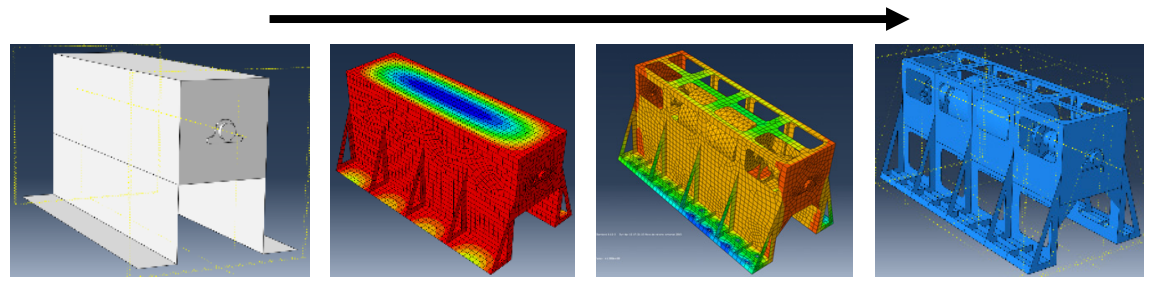

Figure 10: Some steps of the optimisation process.

Metal joints could cause a problem because of the stresses. For this reason, a welding analysis in the joint under maximum stress was carried out in order to check the resistance (fig 11).

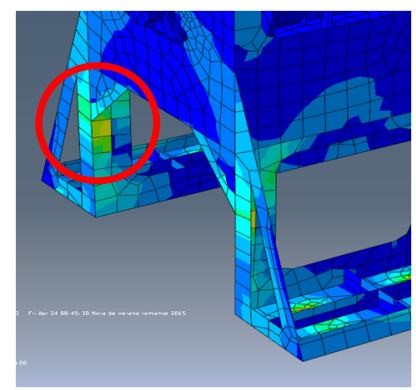

Figure 11: Joint under maximum stress. 
This joint is considered a filled weld because of the right angle. The calculation was done based on the directional weld method in order to check the weld resistance [18]. This method establishes that the resistance of the fillet weld will be sufficient if the following two conditions are satisfied:

$$
\begin{gathered}
\sqrt{{\sigma_{\perp}{ }^{2}+3\left(\tau_{\|}{ }^{2}+\tau_{\perp}{ }^{2}\right)}} \leq \frac{f_{u}}{\beta_{w} \gamma_{M w}} \\
\sigma_{\perp} \leq 0,9 \cdot \frac{f_{u}}{\beta_{w}}
\end{gathered}
$$

Eqns (2) and (3) involve the following parameters; most of them were obtained in the FEM analysis:

- $\sigma_{\perp}$ : the normal stress perpendicular to the critical plane of the throat.

- $\tau_{\perp}$ : the shear stress (in the critical plane of the throat) perpendicular to the weld axis.

- $\tau_{\|}$: the shear stress (in the critical plane of the throat) parallel to the weld axis.

- $\quad \beta_{w}$ : the correlation factor of the steel.

- $f_{u}$ : the ultimate strength of the steel.

- $\quad \gamma_{M w}$ : the global factor of safety.

The obtained results satisfied the conditions shown in eqns (2) and (3). The required weld size (leg length) as $4 \mathrm{~mm}$ was also obtained.

\subsection{System modelling}

The last part of the work was focused on the developed system modelling using AutoCAD software. Commercial and non-commercial elements were modelled considering real dimensions (as shown in fig. 12). Only one track was modelled, but it is clear that by simmetry it is possible to obtain a bidirectional means of transport. Fig. 12 also shows the detail of the traction-fixing system, which has been developed in this work. As has already been said, the carriage includes four traction-fixing system, each one with two steel wheels. SAFEGE infrastructure was also modelled, which allows the monorail to be suspended.

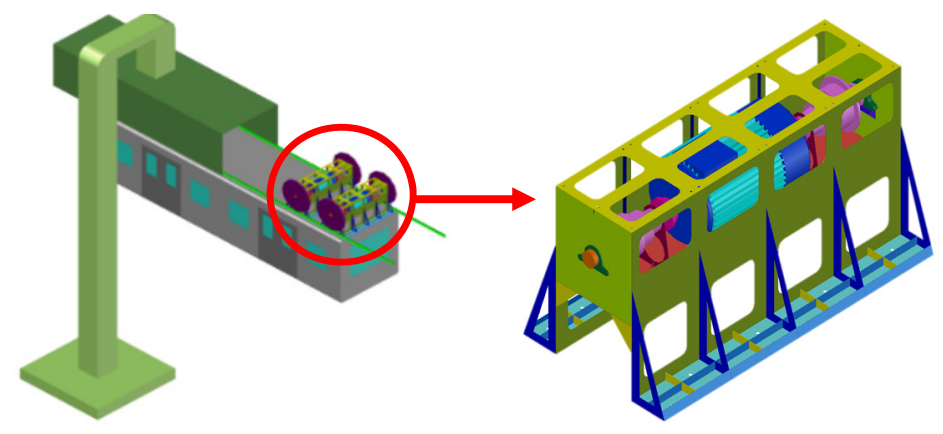

Figure 12: 3D modelling. 


\section{Results}

The results of the FEM analysis under the worst load condition are shown in figs 13 and 14. Fig. 13 shows the displacement diagram while fig. 14 shows the Von Misses stress diagram.

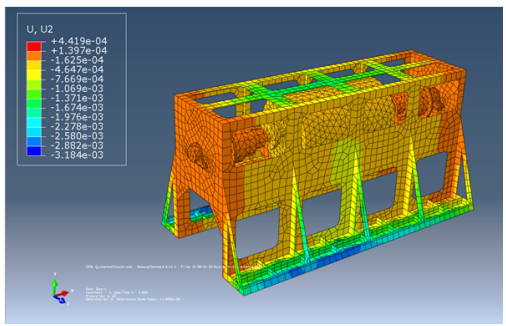

Figure 13: Displacement analysis.

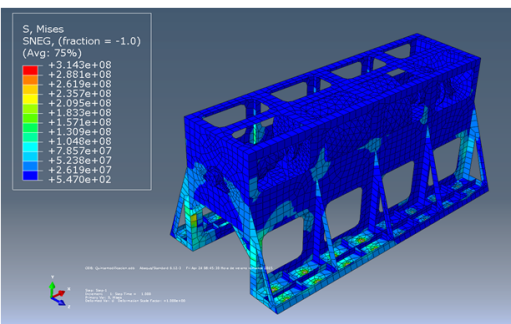

Figure 14: Stress analysis.

Overall, it can be seen that maximum stresses and displacements are located at the base of the bolt and the steel sheet where they are placed.

The thermal analysis proposed (between $-10^{\circ} \mathrm{C}$ and $50^{\circ} \mathrm{C}$ as extreme temperatures) did not show significant results for any temperature. The displacement variation obtained was close to $10^{-2} \mathrm{~mm}$. In comparison with the worst load condition analysis, this is not relevant. Stress results were also insignificant (close to $10^{-2} \mathrm{~Pa}$ ). Thus, thermal analysis has no relevance.

The aim of the modal analysis was to study dynamic behaviour of the structure, mainly the period of vibration under excitation. Results show frequencies between $22 \mathrm{~Hz}$ and $33 \mathrm{~Hz}$ in the first ten vibration modes, which must be considered in order to analyse resonance phenomenon. It should be pointed out that the frequency of $50 \mathrm{~Hz}$, which could cause this phenomenon with other elements such as engines, is in vibrate mode 29 , which has no relevance.

The factor of safety, for the worst load condition, is over 1.75 for any load condition. Note that the minimum factor of safety was established as 1.5. The analysis for load condition with passengers evenly distributed and lateral wind load, shows the highest factor of safety (2.7) with maximum Von Mises stress close to $200 \mathrm{MPa}$. The maximum displacement obtained, after all of the analyses, was $5 \mathrm{~mm}$. Finally, it should be indicated that the convergence of the model was checked, and the mesh size for all FEM analysis was fixed in $6 \mathrm{~mm}$.

\section{Discussion}

Fig. 15 illustrates the front view of the new means of transport. It can be observed that thanks to the traction-fixing system design (which has been made taking into account the future installation in SAFEGE infrastructure) it is possible to ensure a minimum safety distance between the SAFEGE steel box and the carriage.

The system could also be adapted so that there are less traction systems for each carriage, similar to the tilting trains' technology, because the system is 


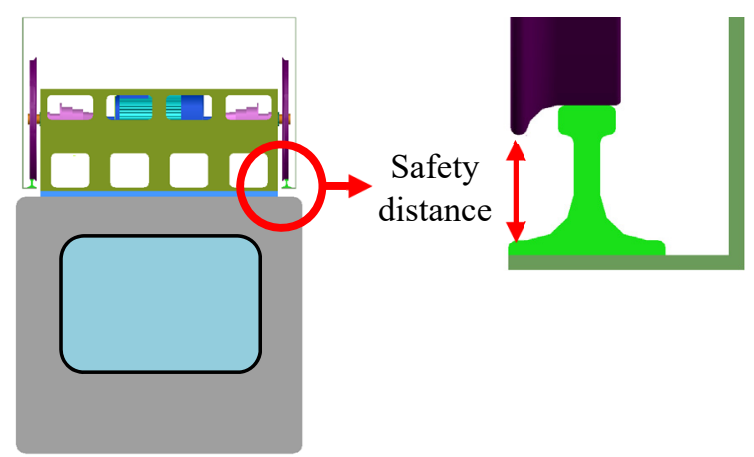

Figure 15: Detail of the safety distance.

independent. They could also incorporate suspension, it if were needed, to stabilise the system, because the design of the traction-fixing system makes it possible to incorporate other elements.

Just like the existing models to date, the developed proposal is not the final solution, but the first step of a different design that improves a priori most weaknesses of the studied systems (e.g. it is symmetrical and improves the safety of WS monorails).

\section{Conclusions}

Developments in monorails as a means of transport throughout history have been increasing. This is due, in large part, to the great potential of the concept itself, whether it be maglev, straddle-type or suspended monorail.

In this paper, different, current systems have been studied, providing an overview to clarify the strengths and weaknesses of each one. The absence of a dominant monorail means that there is good reason to carry out the optimisation proposals that attempt to improve systems weaknesses, as in the case of the described proposal throughout this paper.

The detailed study of the conceptual design has been made, choosing the most relevant parameters, e.g. the capacity or mass of the system. Based on these assumptions, it was possible to select the reduction gears, bearings and couplings, as well as, to calculate the shaft diameter, including fatigue analysis.

Among future lines of work could be discussed the necessity of a suspension system, as well as, the detailed analysis of the wheels and carriage design.

\section{References}

[1] The Monorail Society Official Website, www.monorails.org

[2] H. H. C. Barton, M. A., M. I. Mech. E., M. I. E. E. \& M. Inst. T, Monorails. Journal of the Institution of Locomotive Engineers, 52(285), 1962.

[3] Xihe He, Application and Prospect of Straddle Monorail Transit System in China. Urban Rail Transit, 1(1), pp. 26-34, 2015. 
[4] Liu Xi, Liu Fang-gang \& Sun Huan, Study on the Application and Development of Monorail Transit System. International Journal of Engineering Research \& Technology, 3(5), 2014.

[5] Wang Wei-jie. Analysis of influence factors of straddle type monorail vehicle tire life. Urban Rapid Rail Transit, 22(4), pp. 89-91, 2009.

[6] STC Official Website, http://www.skytraincorp.com/

[7] PRT Official Website, http://www.personalrapidtransit.com/

[8] Mochizuki, T., On the Extension of Urban Area and The Introduction of a New Transportation System, Automated People Movers II, 646-655, 1989.

[9] Lindsey, H., Operational Characteristics of Urban Monorail System, Automated People Movers VI, 193-201, 1998.

[10] Li Gang Li Pei, Overview of the development and use of a vehicle tire track system. Railway Locomotive \& Car, 33 (10), 53-58, 2013.

[11] Iguadix, http://www.iguadix.es/content/wuppertal-schwebebahn

[12] Fanopabo, http://www.fanopabo.com

[13] Xiao Jun. Analysis on the adaptability of monorail transit. Electric Locomotives and Mass Transit Vehicles, 36(4), pp. 20-23, 2013.

[14] Childs, P., Phil, D., Eng, C., Mech, F.I \& Hons, BSc., Shafts (Chapter 2). Mechanical Design Engineering Handbook, ed. Butterworth-Heinemann, pp. 255-315, 2014.

[15] ASM metals handbook. Properties and selection: irons, steel and highperformance-alloys, vol. 1. Metals Park $(\mathrm{OH})$ : American society of metals; 1990.

[16] Gujar, R. A. \& Bahskar, S. V., Shaft Design under Fatigue Loading By Using Modified Goodman Method. International Journal of Engineering Research and Applications, 3(4), pp. 1061-1066, 2013.

[17] Marudachalam, D., Kanthavel M.G,K., Krishnaraj, R., Optimization of shaft design under fatigue loading using Goodman method, International Journal of Scientific \& Engineering Research, 2(8), 2011.

[18] Singh, R., Welding and Joining Processes (Section 2, Chapter 3). Applied Welding Engineering: processes, codes and standards ed. ButterworthHeinemann, pp. 147-170, 2012. 